\title{
Existencia y PRESENCIA de MaÍn XiMÉNEZ EN LA VIDA Y OBRA DE Porfirio Barba JacoB*
}

\author{
Existence and Presence of Maín \\ Ximénez in the Life and Work of \\ Porfirio BARba Jacob
}

\footnotetext{
* Artículo derivado de la beca posdoctoral 2021I del Instituto de Investigaciones Filológicas de la Universidad Nacional Autónoma de México (unam).
}

Cómo citar este artículo: Zuluaga Hernández, E. A. (2022). Existencia y presencia de Maín Ximénez en la vida y obra de Porfirio Barba Jacob. Estudios de Literatura Colombiana 50, pp. 37-54. DOI: https://doi.org/10.17533/udea.elc.n50a02

1 https://orcid.org/0000-0002-5647-6839 esnedy@gmail.com

Universidad Nacional Autónoma de México, México

Editores: Andrés Vergara Aguirre, Christian Benavides Martínez

Recibido: 28.07 .2021

Aprobado: 22.10.2021

Publicado: 17.01 .2022

Copyright: (92022 Estudios de Literatura Colombiana. Este es un artículo de acceso abierto distribuido bajo los términos de la Licencia Creative Commons Atribución No comercial - Compartir igual 4.0 Internacional

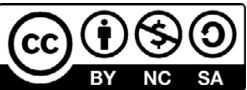

\author{
Esnedy Aidé Zuluaga Hernández ${ }^{1}$
}

Resumen: Maín Ximénez es el primer seudónimo del poeta colombiano Porfirio Barba Jacob. Mediante un recorrido biográfico por su infancia y primera juventud, rastreo los orígenes de Maín desde la correspondencia, escritos autobiográficos y archivos de la época. Indago en las publicaciones en que aparece y en el tránsito del plano real al literario para entender el sentido y la trascendencia del nombre. Atiendo a su nacimiento poniendo atención en la forma como Maín migra al poema para entrañar su proyecto poético, gestado desde un ambiente rural agreste con la creación de Maín en el centro de sus preocupaciones escriturales.

Palabras claves: Porfirio Barba Jacob; Ricardo Arenales; Maín Ximénez; poesía colombiana; poética; biografía.

Abstract: Maín Ximénez is the first pseudonym of the Colombian poet Porfirio Barba Jacob. Through a biographical journey across Barba Jacob's childhood and early youth, I trace the origins of Maín considering the correspondence, autobiographical writings and archives of the time. I inquire into the publications in which he appears and examine the transition from the real to the literary plane, in order to understand the meaning and transcendence of the name. I address his birth, paying special attention to how Main migrates to the poem to embody his poetic project, conceived from a wild rural environment with the creation of Maín at the center of his scriptural concerns.

Keywords: Porfirio Barba Jacob; Ricardo Arenales; Maín Ximénez; Colombian poetry; poetics; biography. 
resolví dejar abiertas las puertas del Misterio a Maín Ximénez.

Porfirio Barba Jacob. “Interpretaciones".

Los orígenes de Maín Ximénez se remontan a 1902, en un pueblo del norte de las montañas de Antioquia llamado Angostura, donde el poeta vive su infancia y la mayor parte de su primera juventud. Con este nombre firma algunos trabajos antes de convertir a Maín en el sello de su proyecto creativo, figura protagónica de "Tragedias en la obscuridad" y posteriormente de "Acuarimántima”. Motivo y marca que configura el proyecto escritural de Barba Jacob, referido además en otros trabajos y proyectos que nunca vieron la luz. Esta construcción literaria del "yo" está íntimamente relacionada con el primer seudónimo que se conoce del poeta y del que se conservan evidencias manuscritas. En sus años de iniciación escritural, desde las tierras antioqueñas que lo vieron crecer, firma algunos trabajos como Maín Ximénez, el primer sello que popularizó su trabajo periodístico y literario en un ámbito local reducido a un escaso círculo cultural.

En términos generales, cada nombre fue sepultando al anterior, como bien lo sintetiza Rafael Montoya y Montoya (1962) en “Nota del Editor”: "El mismo creó a Maín Ximénez que destronó a Miguel Ángel Osorio; al Ricardo Arenales que hundió a Maín Ximénez y, por último, al Porfirio Barba Jacob que los eclipsó a todos” (p. 159). Pero ¿̧hay evidencias de una sustitución cronológica y sistemática de Miguel Ángel a Porfirio, nombre que termina refiriéndolos a todos y al final a una única persona o a su "total desintegración" (Vallejo, 2012, p. 435)? Los procesos asociados a estos cambios evidencian su carácter renovador, pero es la aparición de Maín en el contexto de Miguel Ángel y su transición a Ricardo donde se exhibe una complejidad más profunda asociada a la exploración de los alcances del nombre en su vida y obra.

Este asunto ha sido poco explorado, en parte porque pertenece a los años de su infancia y juventud de los que se sabe poco. En la actualidad hay documentación adicional que se puede contrastar con los datos que han circulado por más de un siglo, replicándose información imprecisa e incluso errónea. Es común leer en diferentes estudios que Maín reemplazó a Miguel Ángel y Ricardo a Maín. Pero esa transición no es lineal ni se da en un solo bloque. Las implicaciones del cambio trascienden a la esfera literaria de su creación poética, como lo evidencia en "Acuarimántima”. 
Efectivamente Maín Ximénez es el primer seudónimo del poeta, pero no reemplaza a Miguel Ángel. Ambos nombres tienen una existencia simultánea y desaparecen como identidad nominal cuando adopta en Barranquilla el seudónimo de Ricardo Arenales, que destronó a Maín y a Miguel Ángel. Ricardo reemplaza a Maín y a Miguel Ángel de la misma forma que Porfirio lo hace con Ricardo, en los términos exactos que apunta Montoya y Montoya. La diferencia radical con Maín es que escala del plano de la vida al literario, específicamente al de su poesía, y se convierte en el germen de su gran proyecto cifrado en el nombre, el vínculo esencial con su país, con su origen, vigente en su producción poética y que además inaugura el perfil vagabundo y en constante búsqueda en sus poemas.

Para los fines de este entramado que teje el poeta con sus seudónimos, pero principalmente de la construcción literaria en la que cifra a Maín, es determinante atender a esta figura protagónica de su poesía. En "La divina tragedia. El poeta habla de sí mismo", ${ }^{1}$ refiriéndose a la "Parábola del retorno" señala: "posteriormente hube de incorporar en el Maín Ximénez” (Barba Jacob, 1933a, p. 12). ${ }^{2}$ Después cita el poema "Lamentación de Maín Ximénez" (p. 15) y y más adelante lo menciona como personaje: "Y, sobre todo, voy a cantarme a mí mismo. Si en tales canciones hay obscuridades, algún día las aclarará mi tragicomedia de Maín Ximénez. Y si hay misterio... ipues si hay misterio no habrá quien lo aclare nunca jamás!” (p. 32). E1 escritor se entrega en el diseño y descubrimiento de "Maín en sus andanzas" (p. 32), la gran apuesta en la que se proyecta.

Es sin duda Maín Ximénez el punto de fuga de su proyecto poético, la fuente de su profundidad artística. A su concepción, creación y alcances atiendo, primero, al rastrear los orígenes de su antecesor Miguel Ángel Osorio Benítez, nacido el 29

"La divina tragedia" agrupa dos textos que abren Rosas Negras (Barba Jacob, 1933b), el segundo libro publicado del poeta bajo la edición de Rafael Arévalo Martínez: "La divina tragedia. El poeta habla de sí mismo" (pp. 1-33) y "La divina tragedia. Fragmentos del prólogo de 'La Diadema'. Libro próximo a ser publicado" (pp. 34-35). Es el primer texto el que se conoce como "La divina tragedia", fechado en "Octubre, 6 de 1920" (p. 33). El segundo, como el título lo indica, contiene "fragmentos" de un "prólogo", "(Composición tomada de un diario quezalteco)" (p. 35), según se indica en la misma edición.

2 Nótese que acá referencia un libro, el gran proyecto de Barba Jacob.

3 Uno de los poemas perfectos del proyectado gran volumen: “¡Entonces pondré en formas mejores la emoción y el ensueño que provisionalmente dejo en éstas! Tal es la historia de mi 'Lamentación de Maín Ximénez' - que sirve de Pórtico al libro. Es una poesía perfecta porque tiene una alta tónica moral, una gran tragedia de la razón, una gran tragedia del sentimiento, una gran riqueza de melodías en sus interludios, y una gracia en las proporciones que la hace parecer una capilla gótica. ¡En ella está simbolizada una divina tragedia!" (Barba Jacob, 1933a, p. 15). 
de julio de 1883 en Santa Rosa de Osos, pueblo de exuberante naturaleza ubicado en la subregión norte del departamento de Antioquia, con una notable producción agrícola y ganadera. Entre 1864 y 1905 fue la capital del Norte antioqueño, cuando el departamento de Antioquia era un Estado Federal dentro de Colombia. En la actualidad sigue siendo uno de los pueblos más importantes del norte junto a Yarumal. A los tres meses de nacido, sus padres (el abogado Antonio María Osorio y la maestra de escuela Pastora Benítez) ${ }^{4}$ emigraron a la capital en busca de mejores oportunidades, dejando el niño a cargo de sus abuelos paternos (Benedictina Parra de Osorio y Emigdio Osorio) en Angostura, un pueblo pequeño y de difícil acceso, donde el poeta vive la infancia en las bondades del campo y la adolescencia en medio de las carencias intelectuales propias de un poblado alejado de la capital e internado en las montañas.

Entre 1889 y 1895 cursa estudios primarios en la escuela pública de Angostura. Al finalizar, con doce años, emprende su primer viaje a la capital para conocer a sus padres. Con ellos vive dos años (Jaramillo Meza, 1972, p. 12), pero su experiencia no es nada grata como él mismo lo relata en "La divina tragedia", una confesión que resume el panorama de la familia en Bogotá y las relaciones afectivas del niño con sus padres, que perduran en el recuerdo del poeta. En 1897 regresa con sus abuelos a Angostura y a los dos meses lo envían a Medellín a estudiar en la Escuela Normal. Abandona sus estudios a los pocos meses y regresa al pueblo con sus abuelos por unos días, antes de emprender su segundo viaje a Bogotá. En la capital estudia Derecho en la universidad, pero renuncia muy rápido para regresar de nuevo a Angostura (p. 14).

Hay pocas evidencias que permiten reconstruir las andanzas del poeta en estos primeros años, pero en el Archivo de Angostura se conserva una carta del 12 de febrero de 1899 que da cuenta de su segunda estancia en la capital. La misiva es de su madre, Pastora Benítez, a María Jesús Cadavid de Benítez, abuela materna del poeta, desde Zipaquirá. ${ }^{5} \mathrm{El}$ inicio prueba la reciente llegada de los hijos, las condiciones en las que arriban y la persistencia de las precariedades económicas de la familia que

$4 \quad$ En el Archivo de Santa Rosa de Osos, Libro de posesión de empleados para el año1883, se conserva el nombramiento de "la señora Pastora Benítez de O", el 7 de mayo, como "Directora en propiedad de la Escuela Elemental de niñas de este distrito”. Es importante señalar que Pastora estaba a menos de tres meses de dar a luz a Miguel Ángel en la misma escuela. Hoy no hay ninguna duda de que el poeta nació en Santa Rosa, como lo demuestra el acta de bautismo que reposa en el Archivo.

5 Municipio del departamento de Cundinamarca ubicado a 29 kilómetros de Bogotá. 
el joven ya había experimentado en el primer viaje: "Rafael y Miguel Ángel permanecieron encerrados unos días porque no trajeron ropa siquiera regular, tan siquiera trajeron calzado, cosa que me afligió, pues yo no esperaba ese gasto y no tenía medios de conseguir" (Benítez, 1899).

Después de esta estancia de dos meses, según Jaramillo Meza, regresa a Angostura a iniciar su ejercicio de maestro, entre 1898 y 1899, aunque según las fechas debió ser en abril de 1899, como ayudante de la escuela dirigida por Lino Alarcón. El poeta afirma en "La divina tragedia" que estuvo un año en la Normal y su retiro fue a causa de la Guerra de los Mil Días (Jaramillo Meza, 1972, p. 4), iniciada el 17 de octubre de 1899. No hay evidencia de la fecha de reclutamiento, pero según Jaramillo Meza es 1901. Quizás por su papel al margen de las balas, los horrores de la guerra parecen no haberlo impactado tanto como la magnificencia de la naturaleza y la experiencia concreta del sentido de la participación de los civiles.

Un dato interesante de estos años tiene que ver con sus habilidades literarias: "Miguel Ángel Osorio, Capitán ayudante mayor del Batallón Santa Rosa N 2" (Jaramillo Meza, 1972, p. 25), escribe por encargo el 5 de mayo de 1902 un informe de "las peripecias del combate de Santa Rita" (p. 21) ocurrido los días 19, 20 y 21 de abril. El relato es publicado el 31 de mayo de 1902 en El Repertorio Oficial, órgano del Gobierno del Departamento de Antioquia, y va dirigido al "Coronel Julio C. Gamboa V., Comandante de las Fuerzas estacionadas en Santa Rita” (p. 18). La voz oficial de las filas conservadoras describe el asalto de las tropas liberales a la aldea de Santa Rita, a los "soldados revolucionarios" que a la cabeza del "guerrillero Manotas" saquean y destrozan todo lo que encuentran a su paso (pp. 18-19). Terminada la guerra regresa a Angostura, retoma su profesión de maestro y pasa a ocupar el cargo de director de la escuela de varones, como lo demuestra una breve carta manuscrita del 20 julio de 1901 conservada en los archivos del pueblo, donde le expresa al alcalde su disposición para ocupar la vacante.

Según estos registros, entre octubre 17 de 1899 y noviembre 21 de 1902, tiempo que duró la Guerra de los Mil Días, el poeta es reclutado y participa por un periodo de año y medio, según sus propias declaraciones. Es posible que su participación en la guerra haya tenido diferentes frentes, porque en febrero de 1902 ya circula su periódico El Trabajo, y en abril registra el combate de Santa Rita. Según Jaramillo Meza, en julio de 1901 estaba solicitando al alcalde la vacante de la Escuela Pública 
de varones.

Junto a su desempeño de maestro continúa con el proyecto literario concretado en la escritura de sus primeros poemas y la actividad periodística asociada a La Luz y El Trabajo, ${ }^{6}$ que tiene como antecedente la narración de los sucesos del combate de Santa Rita. En estas publicaciones reseña eventos cotidianos del pueblo, difunde asuntos de orden cultural, literario y filosófico, expresando su preocupación por la educación, en calidad de maestro comprometido con el proceso educativo de sus estudiantes. Su crítica al sistema de educación es incisiva, una incontable lista de carencias que desbordan las aspiraciones altruistas del joven que apenas llega a los veinte años.

Estos periódicos manuscritos debieron circular desde principios de 1902 y hasta el 14 de junio de 1903, fecha en la que, en una carta, ${ }^{7}$ el poeta se despide de su amigo de infancia Francisco Mora Carrasquilla al marcharse de Angostura a Medellín y luego a Bogotá. Casi dos años después de fundados sus periódicos locales, el poeta traslada su sueño editorial a la capital. El 14 de febrero de 1904 circula el número inaugural del Cancionero Antioqueño en Bogotá, la primera revista cultural que funda el poeta, pues las publicaciones anteriores eran manuscritos de poco alcance. A mediados de julio la revista desaparece por no ser rentable y Miguel Ángel regresa a su tierra natal.

De La Luz se conserva la portada del primer ejemplar manuscrito con las siguientes indicaciones: "Redactor responsable, M. A. Osorio. Serie I. Angostura. Marzo 15 de 1903. Número 1”. La portada funciona como editorial, además de ser lo único que sobrevive de una serie de publicaciones que desconocemos. Formula en términos editoriales un propósito que empieza identificando como clave para el progreso las diferencias entre los individuos en tanto "pensamientos" e "ideales", con aspiraciones y capacidades que los determinan. Diferencias que posibilitan el “progreso" que se logra "ensayando”, es decir, emprendiendo. Por eso siempre hay que

6 La Casa de la Cultura Porfirio Barba Jacob de Angostura tiene los únicos folios que se conservan de estas dos publicaciones, casi desconocidas. Alfonso Mora Naranjo (1962) menciona que El Estudio es otro periódico del poeta (p. 123), pero las referencias en la historia del periodismo en Antioquia confirman que La Luz y El Trabajo son de Barba Jacob, mientras los tres periódicos titulados El Estudio están identificados con otro redactor. Esta información es corroborada por Heriberto Zapata Cuéncar en su libro Antioquia, periódicos de provincia (1981) y citada por María Cristina Arango de Tobón en Publicaciones periódicas en Antioquia 18141960: del chibalete a la rotativa (2006).

7 Con esta carta abre la correspondencia del poeta recogido por Vallejo. Hoy se conocen manuscritos anteriores, de 1901 y 1902.

$8 \quad$ Parte de esta cuartilla es publicada por Arango de Tobón (2006, p. 204). 
celebrar la "obra" del otro sin excluir la "crítica”. Con estas consideraciones de orden filosófico, del hacer por oposición a la quietud vacía, Miguel Ángel presenta La Luz a un público lector muy reducido y posiblemente poco versado en los asuntos de la "luz en el pensamiento".

Antes ya circulaba en Angostura otro periódico del poeta: El Trabajo. Se conserva el ejemplar del 30 de marzo de 1903, "Serie II. Números. 10 y 11. Redactor Responsable. Maín Ximénez", “Contenido: El Salón de Lectura - Documentos - La Escuela tal como debe ser - Ayuntamientos - Crónica Menuda - Magníficat - Carta - Amanecer - Variedades". Estas indicaciones de la portada dan cuenta de la continuidad de la publicación y de la variedad de temas tratados para llegar a un público más amplio y diverso, aunque en los límites de su pueblo y bajo los requerimientos locales.

La edición de Obras completas (1962), a cargo de Rafael Montoya y Montoya, publica apartes de El Trabajo bajo el título "Prosa Inédita”(Barba Jacob, 1962, pp. 437-446). Impresiona el grado de reflexión y conciencia frente a la necesidad de una educación digna, producto de la formación autodidacta. Nótese el sentido esteticista del joven maestro de veinte años: "tres son las condiciones principales que requiere el local: comodidad, amplitud y elegancia. En cuanto al mobiliario, debe ser: proporcionado, suficiente y hermoso" (p. 444). Estas condiciones del aula de clase son formuladas desde la propia experiencia que "hace diez años" tuvo asistiendo a "la Escuela de su pueblo" (p. 444) y las cuales recuerda en estos términos desde su posición actual: "Ahora que soy grande, y cuando he sido ya maestro, he conocido la importancia de la comodidad en la Escuela. Un salón incómodo es una penitencia para los alumnos, y en él difícilmente podrá haber buena disciplina” (p. 444).

En este contexto aparece la novela corta Dimitas Arias (1897) de Tomás Carrasquilla (1858-1940), que retrata la cruda problemática de la educación con la que dialoga el joven maestro desde su posición de educador y su experiencia como alumno. Es importante atender a las fechas. Estamos en 1903, la novela de Carrasquilla se publica apenas siete años atrás (1897) y la vida escolar que retrata es la antioqueña de las últimas tres décadas del xıx, muy cercana a la experiencia escolar del maestro diez años atrás (1893). Dimas Arias, un inválido que la Iglesia convierte en maestro de escuela para librarlo del hambre, recibe de salario mensual las viandas que las familias le ofrecen a cambio de la educación de sus hijos, niños de trabajadores campesinos que son la expresión de toda carencia material y el descuido de sus padres. Entre "la mugre y el olor" se 
erige la escuela de instalaciones miserables, casi inexistentes (Carrasquilla, 2018, p. 249).

Contra este modelo Miguel Ángel plantea la concepción esteticista de la escuela desde el espacio y su dotación, pero acompañada de señalamientos como la "inestabilidad de maestros y estudiantes" (Barba Jacob, 1962, p. 445). El excesivo cambio de maestros y la entrada y salida constante de los estudiantes durante un periodo escolar entorpecen la continuidad de los procesos de aprendizaje; además insiste en "la falta casi absoluta de textos, mapas, cuadernos, apartados de física y química, herramientas" (p. 446), que el Estado debería proporcionar.

Respecto a la importancia del mobiliario en las escuelas, el joven maestro trasciende lo material y establece la directa relación con los procesos de aprendizaje citando apartes del "Discurso de M. Labouyase" titulado "Horace Mann", 9 para concluir que "son indispensables para que la Escuela llegue a elevarse a la altura que necesita para llenar su objeto remediando una necesidad suprema - el ennoblecimiento del linaje humano por medio de una educación general-” (Barba Jacob, 1962, p. 441). Lo que pretende el poeta es teorizar sobre "un compendio de las doctrinas pedagógicas”, pero es consciente del rigor "verdaderamente científico" que requiere el asunto de la educación y por eso da cuenta de los interlocutores a los que busca llegar: "A la municipalidad de mi pueblo someto este fruto de mis intenciones en favor de la instrucción popular"(p. 441).

Retomando de nuevo los periódicos, ambos circulan por algún tiempo de manera simultánea. Mientras en La Luz publica bajo el nombre de Miguel Ángel, en El Trabajo lo hace como Maín. Este dato es importante porque nos lleva a los orígenes de este especial seudónimo y a un carácter institucional de su trabajo periodístico muy direccionado a la escuela. Una de las pruebas que lo sustenta es una carta del 5 de febrero de 1902 en la que el poeta solicita permiso a la Alcaldía para publicar El Trabajo, a la vez que adjunta un ejemplar. El poeta presenta el volumen inaugural del periódico, o mejor revista cultural, a las instituciones locales con el fin de que aprueben la divulgación de este trabajo, aunque ya circulaba entre la pequeña población, como lo demuestra un manuscrito, anterior a la carta, del 17 de enero de 1902 y que se conserva también en el Archivo de Angostura.

Es posible que Miguel Ángel hubiera tenido problemas con las autoridades ción. El periódico argentino del Consejo Nacional de la Educación lo publica en El Monitor de la Educación Común el 15 de mayo de 1889 (pp. 795-802). 
locales por sus publicaciones, de ahí se entiende el asunto de la carta, más antigua que la nota fechada el 14 de junio de 1903, dirigida a su amigo de infancia Mora Carrasquilla (Barba Jacob, 1992, p. 11), hasta hoy la más antigua publicada. Con esta misiva, Vallejo (1992), el editor de Cartas de Barba Jacob, abre la colección que recopila y anota: "Es uno de los pocos testimonios del pasajero pseudónimo Maín Ximénez que el poeta adoptó a comienzos de 1903, por corto tiempo" (p. 11). Otro dato que registra Vallejo de las huellas de Maín, seudónimo vigente por lo menos entre 1902 y 1906 como las fuentes lo señalan, proviene de Luis Madrigal Medina, discípulo del poeta en Angostura, que publicó en el diario de Medellín Hoy, el 2 de mayo de 1959, el poema “El retorno”, "señalando que el poeta lo compuso como una imitación del poema del mismo título y motivo del español Vicente Medina, y con la firma de Maín Ximénez" (Vallejo, 2006a, p. 305).

El otro registro de Maín aparece en la revista literaria Cancionero Antioqueño (1904). En su carácter de director, Miguel Ángel Osorio anuncia: "En uno de nuestros próximos números [se publicará] Virginia, ${ }^{10}$ preciosa novelita de Maín Ximénez" (Barba Jacob, 2016, p. 54). Esta novedad, entre otras, aparece al final del segundo número promocionando una obra que no se publica en la revista ni en otro medio conocido. Tampoco se conserva el manuscrito que circuló entre algunos habitantes de Angostura.

De la existencia de la novela contamos con el testimonio de Alfonso Mora Naranjo (1898-1964), alumno “allá en Angostura, en la Escuela de la Iniciación que fundó el poeta” (Vallejo, 2012, p. 173), que opinaba que, si bien Miguel Ángel Osorio era considerado "un mal maestro de escuela en Santa Rosa, según dicen personas que conocieron su actuación en aquella ciudad; [era] un excelente maestro en Angostura, en su Colegio Inicial” (Mora Naranjo, 1962, p. 122). Al respecto, Vallejo (2006a) sostiene que su desempeño como maestro en Santa Rosa se da "en la segunda mitad de 1904" (p. 306), pero lo cierto es que el 14 de julio es "nombrado Director de Sección Superior de la Escuela de Varones”, como consta en el Libro de posesión de empleados para el año de 1905, conservado en el archivo de Santa Rosa. Trabajo en el que estuvo aproximadamente seis meses, porque a principio de enero de 1906 tomó posesión del

\footnotetext{
10 A la obra, nunca publicada, se refiere específicamente Jaramillo Meza (1972) en un breve apartado, "La novela Virginia" (pp. 31-33), donde cuenta que Cancionero se hizo inviable económicamente. Esa es la razón de su desaparición y el de los pocos volúmenes concretados.
} 
nombramiento de maestro en Angostura. Además, el 3 de julio de 1904 publicó el último volumen de Cancionero y es posible que se haya quedado un tiempo más en Bogotá, después del fracaso económico de su revista y antes de emprender el viaje de regreso a su tierra natal.

Otro de los pocos testimonios de su desempeño como maestro se encuentra en Oro y verbena, de su paisano Pedro Rodríguez Mira (1946), quien señala que la presencia del poeta en Santa Rosa causó

[...] entre sus discípulos el culto a la belleza y el amor por las cosas del arte, y logró formar, con sus mejores alumnos, un grupo escénico que alcanzó a representar comedias y algunos dramas, entre éstos uno titulado "la Muerte de Córdova", compuesto por el propio Barba Jacob y que quizá su autor no juzgó después digno de ser publicado (p. 55 ).

Además, Rodríguez Mira transcribe unos versos que hacen parte de la obra y que Vallejo (2006a) publicó como poema con el título "Morir... Morir tan joven”, “dictados tal vez por alguno de los alumnos de Miguel Ángel” (p. 306).

Hay certeza, de los archivos de Angostura, que el 4 de enero de 1906 es "nombrado Director de la Escuela de Varones” y el 19 del mismo mes le escribió una carta manuscrita al Presidente del Concejo Municipal en la que expone el lamentable estado del salón: "hay desperfecto en el techo, lo cual ha originado goteras que son una amenaza para los libros y útiles del establecimiento, así como para la tranquilidad y buen orden en la clase" (Barba Jacob, 1992, p. 14). La otra carta que se conserva es del 16 de febrero, esta vez dirigida al alcalde Constantino Balvín para exponerle la misma problemática de los desperfectos e insuficiencia inmobiliaria del "local de la Escuela", nada lejana a las descripciones de Carrasquilla en Dimitas Arias que el poeta ya había referido en 1903 en El Trabajo.

Esta última estadía en Angostura concreta el perfil del maestro esteta, atento a suplir las necesidades materiales de la escuela, sin las que es imposible pensar en educación efectiva y de calidad, nuevamente asuntos ya atendidos en El Trabajo. No hizo tan mal su labor el maestro, cuando tiene la recompensa de que se conozca parte de su producción inicial gracias a alumnos como Mora Naranjo, que memorizó apartados de la composición romántica Virginia.

Jaramillo Meza retoma el testimonio de Mora Naranjo para incluir en su biografía esos párrafos aprendidos, a los que adicionó la "conminación" conservada en la alcaldía de Angostura, que obligó al joven maestro a entregar el material para 
destruirlo. Maín es el autor y el protagonista de Virginia, el germen del hombre de letras, pero lejos de reemplazarlo, Miguel Ángel y Maín tuvieron una coexistencia simbiótica marcada por el deseo de trascendencia a través de la producción artística y la divulgación cultural. En los números que alcanza el Cancionero, ${ }^{11}$ la única aparición de "Maín" es la que refiere a la novela, mientras "Miguel Ángel Osorio" está en la portada de cada uno de los volúmenes bajo la figura de director, además de ser el autor de algunas colaboraciones que firma con sus iniciales “M. A. O.”. Juan José Escobar López (2016), quien reedita y prologa el Cancionero, advierte en ese asunto al referirse al anuncio de la "novelita":

[… a excepción de esta única mención del seudónimo Maín Ximénez no hay otra en el Cancionero. Miguel Ángel Osorio aún no firmaba con seudónimo sus escritos, pues al leer todos los números de esta revista podemos advertir: I) que firmaba las notas, biografías, circulares y dictámenes legales de la revista con su nombre propio; 2) que firmaba sus escritos literarios, poemas (Ns. 4 y 5 ) y prosas $(8,9$ y 10) (p. 54).

Este hecho pone en evidencia que Maín Ximénez como seudónimo no reemplazó a Miguel Ángel Osorio Benítez. Jaramillo Meza (1972) citó el Cancionero para señalar que su creación coincidió con la adopción de Maín Ximénez (p. 26), y además lo asoció con los poemas que le escribe a Teresita (p. 34). Es común que esta primera etapa de su despertar literario se homologue con Maín, pero antes del Cancionero el poeta ya firmaba con ese seudónimo. Es evidente que el sentido de estos cambios transciende esa horizontalidad planteada en primera instancia.

En este punto, Vallejo, citado por Escobar López (2016), hila muy fino al afirmar que "Maín Ximénez, más que un seudónimo fue el personaje de un gran poema o drama que se le quedó en proyecto" (p. 18), que pretende dar forma a una reunión de lo mejor de su poesía con la figura de Maín protagonizando ese compendio. El mismo poeta se dio a la tarea de definirlo en uno de los textos en prosa titulado "Interpretaciones", que aspira sea presentación de sus poemas, y que Rafael Arévalo Martínez (1884-1975) incluyó en Rosas Negras (1933): "Maín Ximénez es el personaje fundamental de una tragicomedia mía, y los poemas que forman este libro son glosas o desarrollos líricos, en ocasiones, vagas paráfrasis — de ciertas escenas o pasajes del Maín” (Barba Jacob, 1933c, p. 36). Y más adelante señala ese proyecto nunca 11 Aunque la última publicación fusiona los "números 8, 9 y 10". "Bogotá, domingo 3 de Julio de 1904” (Barba
Jacob, 2016, p. 140). 
concretado, pero en el que cifra su potencial poético bajo la figura de Maín: "En todo el libro hay pasajes así, obscuros, y no se aclararían sino con la lectura del Maín. Desgraciadamente para mi nombre, la publicación del Maín no es posible todavía”(p. 37).

El nombre sobrepasa los límites del seudónimo. En los primeros y escasos registros que se conocen también está el origen de la figura protagónica de su obra poética, la que siempre estuvo en la mente del creador y en la que cifra todo su potencial escritural. De Miguel Ángel Osorio Benítez a Maín Ximénez hay un rito de iniciación literaria que puede tener su origen en Marín Jiménez, nombre que enrarece y a la vez mitifica al adoptar una variante de dos apellidos comunes en Antioquia.

Se asocian los trabajos de Maín Ximénez a un tono romántico del que se pretende desligar el poeta al llegar a Barranquilla, donde aparece el seudónimo Ricardo Arenales. Mora Naranjo (1962) señala especialmente ese carácter, pues en sus páginas "se percibe el suave soplo romántico de fin de siglo, la ternura de las rimas becquerianas y hasta la sublime ampulosidad del gran abuelo Víctor Hugo" (p. 123). Tono común en los poetas de principios de siglo xx en Colombia. "Teresita”, retrato de su novia de juventud, ejemplifica esta etapa del poeta y puede considerarse una muestra de la poesía de su primera producción, que suele asociarse con Maín. Sigue la clásica forma de soneto bajo una temática amorosa en la que retrata la "tierna", "lozana", "casta", "sencilla", "piadosa", "blanca" mujer ideal que con su amor ha fundido la crueldad de la pena del poeta. El "yo" se concentra en la descripción de un "tú" que es toda perfección, el prototipo romántico de la mujer, es decir, fundamentalmente buena. El poeta le confiesa su amor sublime bajo una situación idílica en la que el amado se dirige a su amada correspondida.

La primera producción del poeta, bajo la firma de Miguel Ángel o Maín, mantiene el mismo patrón estético y temático de "Teresita": temas conservadores y religiosos con un tratamiento romántico. Aunque es insostenible afirmar, como lo hace Mora Naranjo, que su época más fecunda estuvo bajo la firma de Maín. Lo que sí es verificable es que esa construcción nominal será el germen de la creación de la figura heroica de "Acuarimántima". Antes está la referencia literaria en el poema "Campaña florida", escrito en 1907 ya bajo el seudónimo de Ricardo Arenales en Barranquilla. ${ }^{12}$ Maín aparece de forma comparativa para indicar una característica que se repite en otros traba-

El poema fue publicado en El Siglo y en La Joya Literaria. Su extensión inicial, según Vallejo (2006a), alcanza las 23 páginas (p. 320). 
jos: “y pasarán gritando —como Maín Ximénez-”(Barba Jacob, 2006, p. 49). Gritar es una acción recurrente del “yo" que está en los orígenes de Maín y que va a desembocar en el alarido con el que cierra dramáticamente "El son del viento".

Hay que señalar otras dos apariciones importantes de Maín, parte del proyecto fallido que el poeta pretende concretar en Odisea de Maín Ximénez, toda la poesía de Ricardo Arenales (Vallejo, 2006a, pp. 326-327). El primero es "Tragedias en la obscuridad", origen de "Acuarimántima”, con el que comparte versos idénticos de los que destaco dos en los que se nombra y se define a sí mismo desde su condición de poeta y viajero: "Yo soy Maín, el héroe del poema" (Barba Jacob, 2006, p. 75) y "Yo soy aquel viajero transitorio" (p. 78). El segundo poema, "Parábola de los viajeros", como su título lo indica, advierte en el asunto del viaje, medular en su poesía, y ubica a Maín como una de las voces que increpa a los caminantes. Al final los caminos resultan desembocando en el mar, en el siempre vivo misterio de "Acuarimántima”, que todo lo desborda.

De Maín Ximénez a Ricardo Arenales hay un deseo de apartarse de una producción inicial en la que se ve y se siente romántico frente a la potente creación que pretende a futuro. De Arenales a Barba Jacob no hay un cambio sustancial en su poesía, pero de Maín a Arenales no solo es evidente, sino que instaura un proyecto literario de largo aliento que pretende desligarse del "yo romántico" para abrirse al “yo modernista”, y por ahí a la modernidad que significa la especial creación de la máscara en el poema autorretrato del modernismo y con ella de la diversificación definitiva del “yo". Además de la importancia de esta transición hay que advertir la construcción transversal del nombre de Maín en el interior de su obra. En principio, como seudónimo encarna los ideales del joven escritor provinciano, convertido en el gran símbolo de la búsqueda que persigue con angustioso deseo.

Maín surge del interés del poeta por encontrarse como artista, de su inconformidad y de la necesidad de concretar un proyecto no muy bien definido pero cifrado en la poesía y configurado en el nombre. Por eso, aunque Maín tuvo una corta vida como seudónimo se instaura profundamente en su obra desde la misma planificación de los nombres con los que sueña titular su gran libro. "Odisea de Maín Ximénez" fue uno de los posibles títulos. Además, Vallejo (2006b) documenta en el "Prólogo" de Poesía completa que estaban, entre otros: "El corazón iluminado, El jardín de las afrentas, Main Ximénez, Motivos de Main Ximénez, Tragicomedia de Main Ximénez, Rosas Negras, La diadema, Guirnaldas de la noche, La vida profunda, Antorchas contra el viento, 
Poemas intemporales" (p. 7).

Ninguno de estos títulos, que entablan un diálogo directo con el grueso de su obra, sale a la luz bajo su cuidado editorial. No es gratuita la repetida presencia de Maín Ximénez, las constantes alusiones teatrales, el sentido pasional de la existencia que proclama, el canto intenso a la vida, la reverencia asidua a la muerte y la intemporalidad que persigue en la poesía. Hay por lo menos tres referencias en sus cartas de fechas muy cercanas que evidencian este proyecto bajo la marca de Maín, que aspira condensar en una antología selecta desde sus propios criterios. La primera es una nota no fechada escrita a Enrique González Martínez, a quien le promete un texto: "te mandaré unas escenas de mi "Maín" (Barba Jacob, 1992, p. 77). La segunda, del 25 de mayo de 1920, al poeta mexicano Rafael López, en la que le confiesa "cómo se urde la tragedia" aprendida desde la realidad mexicana, y a continuación menciona: "Yo ensayé, en la penúltima jornada de Maín Ximénez, una desmandada de un pueblo en masa, en medio de la catástrofe" (p. 79). Y por último la carta a Toño Salazar en julio de 1921 desde Guadalajara, encomendándole un envío: "En una de esas balijas [sic] están varios cartapacios o carpetas, donde guardo los trabajos del 'Maín', el prógolo [sic] de mi libro, apuntes, borradores y otras cosas" (p. 87). Las tres referencias dan cuenta del interés profundo del poeta en la escritura de una obra en la que predomina el carácter totalizante de Maín.

En este orden de ideas cabe mencionar el epígrafe de Maín que encabeza una de las primeras versiones de "Elegía de septiembre" y que conserva Poemas Intemporales. Conecta a Maín con ese contexto rural del que proviene: “ $\mathrm{OOh}$ sol! ¡Oh mar! ¡Oh monte! ¡Oh humildes animalitos de los campos! Pongo a todas las cosas por testigos de esta realidad tremenda: He vivido" (Barba Jacob, 1944, p. 35). El título de este poema remite a un dolor profundo que está latente al final de cada estrofa pero que se resuelve en el último verso de la composición. Ir al olvido a pesar del vivir intenso cierra el sentido de esa lamentación a la que conlleva la elegía. Maín Ximénez es el germen que crece conforme a la grandeza de su obra, marca la salida del poeta de su terruño natal, su despertar literario ya dado por el carnaval.

En el verso "Yo soy Maín, el héroe del poema", hay un grado de conciencia del “yo" para autodefinirse, nombrándose desde las márgenes del texto. La realidad de 
Maín es estructural y atañe exclusivamente al poema, permanece como fundamento de una obra poética preocupada por el entendimiento de "ser poeta". Convertido en el motivo de su poética pasa a ocupar un lugar mítico, su existencia no se reduce al tiempo que el poeta se apropia del nombre, porque incluso, como las fuentes lo corroboran, es breve y lo alterna con el nombre de pila, sino que atraviesa de manera transversal la creación de Ricardo Arenales y Porfirio Barba Jacob, alcanzando en “Acuarimántima” la máxima de esa construcción. Más que un seudónimo, Maín es la gran creación de la figuración del poeta como artista en el poema, una figura medular en su obra que le da transcendencia a sus aspiraciones de grandeza. La tragedia de Maín, sujeta siempre a su condición de poeta, es la máscara más refinada del héroe demoniaco modernista. Maín Ximénez desaparece como seudónimo, pero se perpetúa en su obra poética, se convierte en "Acuarimántima” en la figura heroica de la gran "epopeya de su espíritu” (Posada, 1992, p. 121):

Retumba en mi recuerdo mi alarido, mi estéril tiempo es mi inquietud suprema.

El trágico dolor ha concluido.

Yo soy Maín, el héroe del poema... (Barba Jacob, 2006, p. 26\%).

Ahí la estampa de Maín, reconociéndose en su heroísmo oscuro, en busca de ese lugar enigmático, luminoso y lejano —“Y fulge Acuarimántima a lo lejos...” (p. 258)—.En ese espacio alucinado tiene puesta la confianza — "Fulgía en mi ilusión Acuarimántima” (p. 258)—. El poeta crea y quiere conquistar el lugar que solo parece posible en su ensoñación. Esa suerte de territorio inalcanzable y etéreo - “vago sueño - mi vaga Acuarimántima - / ¿No brilla entre la niebla Acuarimántima?” (pp. 265-266)—, al que nunca llega el héroe demoniaco, es la metáfora de la búsqueda de la perfección. Ambas funcionan como un dispositivo quimérico capaz de encauzar su potencial creativo. Maín tiene claro de dónde viene - "Yo descendí de la antioqueña cumbre" (p. 258)—y va delirante a su "nebúlea, azulina Acuarimántima” (p. 269).

El poeta parte del mismo lugar y comparte un deseo análogo de crear un espacio utópico concretado en el diseño del poema. Lo importante no es que Maín haya conquistado "Acuarimántima”, sino que la creó en el trayecto de su búsqueda. Lo esencial no es que Barba Jacob haya logrado el poema perfecto, lo determinante es que diseña un poema de largo aliento que tarda más de dos décadas en concluir, donde queda constancia de la potencia desgarradora de sus versos, del exquisito gusto por la forma 
y de la conquista del poeta contra el tiempo.

Recuerda Barba Jacob el famoso libro El hombre que parecía un caballo y otros cuentos (1914) en el que su amigo Arévalo Martínez lo retrata: ${ }^{13}$

He de recordar mis relaciones con Rafael Arévalo Martínez, el hemiplégico de mi tragicomedia, mal augur de Maín Ximénez... iMaín Ximénez no se redimió al fin por una mujer, como tú me decías, mi amigo Guatemalteco, sino por virtud del canto! A aquel espíritu lleno de deseo de ver, no de deseo de amar porque la angostura de su moral no se lo permitía, le parecí un sér en extremo raro (Barba Jacob, 1933a, p. Iø).

El extravagante y raro colombiano es equiparado por su amigo a la potente figura de un caballo, animal que está en consonancia con toda la fuerza agreste de sus primeros años en las montañas de Antioquia, pero a su vez con esa faceta de maestro en formación que necesita alumnos para compartir los procesos de búsqueda en los que siempre está inmiscuido y de los que sin duda Arévalo Martínez hizo parte en varios momentos. Este libro es producto de esos encuentros. Al final del cuento, que da título al libro, el narrador describe al señor de Aretal mediante diálogos: "Me confesó un día dolorido, que ninguna mujer lo había amado” (Arévalo Martínez, 1997, p. 12). Y más adelante dice el narrador:

Y ahora oiga mi profecía: una mujer lo redimirá. Usted, obsequioso y humilde hasta la bajeza con las damas; usted, orgulloso de llevar sobre sus lomos una mujer bella, con el orgullo de la hacanea favorita, que se complace en su preciosa carga; cuando esa mujer bella lo ame, se redimirá: conquistará el pudor (p. 12).

A esa profecía se refiere el poeta cuando reafirma su salvación en la poesía en términos del cuento de Arévalo Martínez, pero habla en nombre de Maín Ximénez, no en el de Ricardo Arenales (su seudónimo de entonces). En "Interpretaciones” el poeta vuelve a remitir a esta discusión para tomar distancia del personaje, pero a su vez trasluce el substrato de la creación: "no se me atribuyan a mí todas las quejas de Maín Ximénez, personaje ilusorio en que hay algo de mí mismo, pero tan poco y tan incierto, como lo que hay de mí en el famoso Señor de Aretal, conque a Arévalo

"Dizque era mi caricatura. Yo, francamente, no creo tener la sencillez ni la inocencia del señor de Aretal", afirma el poeta en "La divina tragedia" (Barba Jacob, 1933b, p. 16). El libro de Arévalo Martínez fue el resultado de una profunda admiración por el poeta colombiano y de una intensa amistad. El escritor guatemalteco lo detalla en "Cómo compuse 'El hombre que parecía un caballo". Tema que además explora en detalle Ana María Urruela V. de Quezada en “Génesis y circunstancia de 'El hombre que parecía un caballo’ de Rafael Arévalo Martínez" (1997). 
Martínez le plugo simbolizarme” (Barba Jacob, 1933c, p. 36).

Este reafirmarse en Maín funciona como estrategia para hacer indistinguible el plano literario del real, un interés muy propio de la obra de ambos escritores. El poeta le habla desde un prólogo a Arévalo Martínez, señalando una inconsistencia en el retrato que el guatemalteco propone del colombiano en una construcción literaria. Pero el poeta no se refiere a ese sujeto del cuento con el nombre de Aretal, sino que emplea su primer seudónimo, la construcción del “yo poeta” mejor lograda de Barba Jacob, el gran héroe insatisfecho y pasional de su poesía en constante búsqueda y al que deja "abiertas las puertas del Misterio" (p. 40).

\section{Referencias bibliográficas}

Arango de Tobón, M. C. (2006). Publicaciones periódicas en Antioquia 1814-1960: del chibalete a la rotativa.

Medellín: Fondo Editorial Universidad Eafit.

Arévalo Martínez, R. (1997). El hombre que parecía un caballo y otros cuentos. Madrid: ALLCA XX.

Barba Jacob, P. (1933a). La divina tragedia. El poeta habla de sí mismo. En Rosas Negras (pp. 3-33).

Guatemala: Imprenta Electra, G.M. Staebler.

Barba Jacob, P. (1933b). La divina tragedia. Fragmentos del prólogo de "La Diadema”. En Rosas Negras (pp. 34-35). Guatemala: Imprenta Electra, G.M. Staebler.

Barba Jacob, P. (1933c). Interpretaciones. En Rosas Negras (pp. 36-41). Guatemala: Imprenta Electra, G.M. Staebler.

Barba Jacob, P. (1944). Poemas intemporales. México: Editorial Acuarimántima.

Barba Jacob, P. (1962). Obras completas. Medellín: Ediciones Académicas Rafael Montoya y Montoya.

Barba Jacob, P. (1992). Cartas de Barba Jacob. Bogotá: Revista Literaria Gradiva.

Barba Jacob, P. (2006). Poesía completa. Bogotá: Fondo de Cultura Económica.

Barba Jacob, P. (2016). Cancionero Antioqueño. Medellín: Fallidos Editores.

Benítez, P. (1889). [Carta a María Jesús Cadavid de Benítez], Angostura, 12 de febrero. Copia en posesión del Archivo Museo Porfirio Barba Jacob de Angostura.

Carrasquilla, T. (2018). Dimitas Arias. En Obra escogida (pp. 243-301). Medellín: Editorial Universidad de Antioquia.

Escobar López, J. J. (2016). Introducción. En P. Barba Jacob. Cancionero Antioqueño (pp. 13-21). Medellín: Fallidos Editores.

Jaramillo Meza, J. B. (1972). Vida de Porfirio Barba Jacob. Bogotá: Colcultura.

Montoya y Montoya, R. (1962). Nota del editor. En P. Barba Jacob. Obras completas (pp. 462-466). 
Medellín: Ediciones Académicas Rafael Montoya y Montoya.

Mora Naranjo, A. (1962). Mi maestro era “una llama al viento”. En P. Barba Jacob. Obras completas (pp. 121-158). Medellín: Ediciones Académicas. Rafael Montoya y Montoya.

Posada, G. (1992). Porfirio Barba Jacob, el viajero tempestuoso. México: Instituto Nacional de Antropología e Historia, E1 Colegio de Jalisco.

Rodríguez Mira, P. (1946). Oro y verbena: (Crónicas y cuadros de costumbres de la ciudad de Santa Rosa de Osos). Medellín: Imprenta Departamental.

Vallejo, F. (1992). Notas. En P. Barba Jacob. Cartas de Barba Jacob (p. 11). Bogotá: Revista Literaria Gradiva.

Vallejo, F. (2006a). Notas a los poemas. En P. Barba Jacob, Poesía completa (pp. 303-379). Bogotá: Fondo de Cultura Económica.

Vallejo, F. (2006b). Prólogo. En P. Barba Jacob, Poesía completa (pp. 7-11). Bogotá: Fondo de Cultura Económica.

Vallejo, F. (2012). Barba Jacob el mensajero. Bogotá: Alfaguara. 